\title{
Effects of skin maceration time on the phenolic and sensory characteristics of Bombino Nero rosé wines
}

\author{
Serafino Suriano, Teodora Basile, Luigi Tarricone, Domenico Di Gennaro, \\ Pasquale Tamborra
Consiglio per la Ricerca e la Sperimentazione in Agricoltura, Unità di Ricerca per l'Uva da Tavola e la Vitivinicoltura in Ambiente Mediterraneo, Cantina Sperimentale, Barletta (BAT), Italy

\begin{abstract}
Rosé wines consumption has reached the highest level in present years and it is still an ongoing trend in several countries. Therefore, the production of rosé wines with improved sensory qualities and colour stability would be greatly appreciated. Today, although rosé wines are no longer considered to be less valuable than red and white ones, anyway, because of the past rosés reputation the scientific state of art lacks of specific studies concerning the effects of pre-fermentation maceration times on rosé wines. In this study, different pre fermentation maceration times (3, 6 and $8 \mathrm{~h})$ during production of original location certified and guaranteed rosé wine from Bombino Nero variety (Vitis vinifera L.) were investigated. In all wines standard and specific wine chemical parameters, such as polyphenols, anthocyanins, flavonoids, hydroxycinnamoyl tartaric acids, volatile compounds and colour parameters were determined. A sensory descriptive analysis together with chemical analyses performed revealed that the maceration time significantly affected the aroma, the flavour and the colour of wines. The results showed that, although a longer maceration time is positively correlated to the colour
\end{abstract}

Correspondence: Teodora Basile, Consiglio per la Ricerca e la Sperimentazione in Agricoltura, Unità di Ricerca per l'Uva da Tavola e la Vitivinicoltura in Ambiente Mediterraneo, Cantina Sperimentale, via Vittorio Veneto 26, 76121 Barletta (BAT), Italy.

Tel: +39.0883 .521346 - Fax: +39.0883 .528955 .

E-mail: teodora.basile@entecra.it

Key words: colour, flavonoids, polyphenols, sensory analysis, skin contact, volatile compounds.

Funding: work carried out under the PIF 124 V.I.T.I.S. project, with the financial support from the Regional Development Program 2007/2013, Asse I Miglioramento della competitività nel settore agricolo e forestale, Progetti Integrati di Filiera - Misura 124.

Acknowledgements: the authors would like to thank Torrevento Ltd. Company, Corato (BA), Italy.

Received for publication: 29 0ctober 2014.

Revision received: 23 January 2015.

Accepted for publication: 26 January 2015.

(C) Copyright S. Suriano et al., 2015

Licensee PAGEPress, Italy

Italian Journal of Agronomy 2015; 10:624

doi:10.4081/ija.2015.624

This article is distributed under the terms of the Creative Commons Attribution Noncommercial License (by-nc 3.0) which permits any noncommercial use, distribution, and reproduction in any medium, provided the original author(s) and source are credited. stability of wine over time, however, a lengthener of the maceration is not favourable to enrich the wine with pleasant fruity and flowery aroma compounds, as both the gas chromatography and the sensory analyses showed. It was decided to perform the experimental winemaking processes in an actual winery instead of a laboratory in order to develop a practical winemaking management procedure directly usable for wine producers. The results obtained contribute to improve the knowledge about the importance of selecting the winemaking technique in order to elaborate high quality rosé wines.

\section{Introduction}

Rosé wines production accounted for nearly $10 \%$ of total world wine production in 2011 (Blot and Couderc, 2013). However, the consumption of rosé wines represents a growing trend in the wine market, which is becoming an important part of the total wine market. The rosé wine consumption in the last few years it is been especially increasing in Countries such as France and United States of America (Blot and Couderc, 2013). Their composition varies widely between the light and fruity white wines, low in phenolic compounds, and the coloured red wines, with an high content in anthocyanins and tannins (Di Stefano, 2010). The aroma of rosé wines is principally due to the compounds formed and released during fermentation (Marais, 1983; Baumes et al., 1986), whilst the colour of rosé wines and its stability over time, both depend on the anthocyanins extracted from the berry skins and the reactions involving these compounds and other phenolic compounds during subsequent steps of winemaking and storage (Boulton, 2001; Fuhrman et al., 2001). The production of a rosé wine is difficult, since a minimum of colour has to be extracted along with a maximum level of aromas in a short time. Moreover, since both colour and aromas are fragile and frequently fleeting during storage, the rosé wine must be able to keep its qualities over time (Salinas et al., 2005). Prefermentation maceration of crushed grapes under controlled conditions is a well known procedure performed to enhance the presence of volatile and coloured compounds, extracted from berry skin into wines (Arnold and Noble, 1979; Marais and Rapp, 1988; Cabaroglu et al., 1997). A longer maceration time results in an enrichment in tannins which significantly affect the taste of wine and may require interventions in order to limit astringency, usually associated with the presence of these substances, and the darkening of the colour during marketing (Ramey et al., 1986). Among the most important wine grape varieties grown on the hills of Murgia, which for centuries has been one of the areas of Apulia region (Southern Italy) most suitable for quality wine production (Cappelleri and Lovino, 1986), Bombino Nero is an autochthonous black variety particularly suitable for the production of rosé wines with a typical pink colour, a good acidity and a lin- 
gering note of rose (Tamborra et al., 2003). Bombino Nero rosé wines are particularly appreciated; indeed the original location certified and guaranteed (D0CG) Castel del Monte Bombino Nero vintage 2012 wine was awarded with silver medal at the Mondial du rosé 2013 (http://www.mondial-du-rose.fr/en/index.php?langue=en). The direct pressing (without maceration) of the Bombino Nero grapes yields rosé wines that are initially very subtly intense, elegant and lively, even though during storage these wines undergo a colour change that decreases the qualities of the wine; in contrast, a short maceration is a better premise for greater colour stability (Tamborra et al., 2003). The two parameters to be controlled in order to achieve an adequate level of phenolic compounds and an improved aroma are maceration time and temperature (Ramey and Ough, 1980; Şener and Yildirim, 2013). In white and rosé winemaking maceration temperatures lower than $20^{\circ} \mathrm{C}$ are usually employed (Salinas et al., 2003), since higher temperatures may produce musts with a more intense colour but less colour stability due to a greater propensity to oxidation (Salinas et al., 2005). Previous studies investigating the effects of low temperature pre-fermentation maceration showed that $15^{\circ} \mathrm{C}$ maceration temperature provided wines with the most suitable colour parameters and anthocyanins content, but also most appreciated in an informal sensory evaluation test (Bisson et al., 1980; Salinas et al., 2005). The aim of this study was to improve the colour stability and decrease the aromas alterations of Bombino Nero rosé wine, therefore a low temperature pre-fermentation maceration was performed under controlled conditions with different maceration times $(3,6$, and $8 \mathrm{~h})$.

\section{Materials and methods}

\section{Experimental design}

The winemaking trials for the production of rosé wine from Bombino Nero grape were carried out at the Torrevento winery in Corato (Apulia Region, Italy) during the 2012 vintage. The grapes of Bombino Nero were mechanically harvested in October from vineyards located in the territory of Castel del Monte with vines trained in the espalier system.

\section{Winemaking}

Three batches of grapes (20 t each one) were separately introduced in different reservoirs. In the $3 \mathrm{~h}$ maceration winemaking the grapes were stemmed and crushed at $15^{\circ} \mathrm{C}$ and subsequently introduced in a steel tank at $15^{\circ} \mathrm{C}$ and left to macerate for $3 \mathrm{~h}$. The crushed grapes were pressed and the must was separated from the solid and introduced in a flotation equipment at $15^{\circ} \mathrm{C}$. In the flotation unit most of the oxygen was eliminated and was introduced nitrogen as an inert gas. During this operation the solid fraction of the must was first separated and then removed, thus obtaining a clarified liquid. In the last stage the clarified must was introduced into stainless steel tanks (20 t) and inoculated with a commercial starter culture (Saccharomyces cerevisiae var. bayanus, Uvaferm $\mathrm{BC}^{\circledR}$, Lallemand), previously hydrated in water (15 min, $40^{\circ} \mathrm{C}$ ), to start the fermentation and left a $20^{\circ} \mathrm{C}$. Bombino Nero grape has a high content of polyphenols in the skin (Tamborra and Pigella, 1999), since additional pressure increases the likelihood of astringent and bitter compounds release from grape skins, such as tannins, the horizontal press employed started with less than 1 bar $\left(10^{5}\right.$ $\mathrm{Pa}$ ) of pressure and, in order to perform a gentle pressing, the pressure was gradually increased to a maximum of 4 bars $\left(4 \times 10^{5} \mathrm{~Pa}\right)$ over a course of $2 \mathrm{~h}$. The 6 and $8 \mathrm{~h}$ maceration winemaking procedures followed the same steps of the $3 \mathrm{~h}$ winemaking, but were left to macerate for a different amount of time, according with the test of winemaking to be performed, i.e. 6 and 8 h. Analyses were carried out on wines immediately at racking, and then after 6 and 12 months. During the conventional operations on wine no other substances, apart from sulphur dioxide, were added to the wines.

\section{Chemicals and reference compounds}

Trans-caffeil tartaric acid, trans-p-coumaroyl tartaric acid, caffeic acid, ferulic acid, p-coumaric acid, tartaric acid, malic acid, lactic acid, shikimic acid, quercetin dihydrate, myricetin, kaempferol and 1eptanol were supplied by Sigma-Aldrich, Inc. (St. Louis, M0, USA). The purity of the standards was over 95\%. All the solvents, supplied by Carlo Erba (Milan, Italy), were analytical or high-performance liquid chromatography (HPLC) grade. All the solutions were prepared with distilled deionised water using Carlo Erba reagents.

\section{Grape and wine composition}

At harvest a representative sample of berries was squeezed for measurement of $\mathrm{pH}$, sugar content and total acidity according to the Official European Methods EEC 2676/90 (European Commission, 1990). Total and volatile acidity, reducing sugar, $\mathrm{pH}$, total $\mathrm{SO}_{2}$, alcohol and total dry extract were all determined on wines and on berries (European Commission, 1990).

\section{Polyphenolic and colour measures}

The spectrophotometric analyses of total anthocyanins, monomeric anthocyanins, total flavonoids, flavanols reactive to vanillin and proanthocyanidin were performed on a Perkin Elmer Lambda 25 double beam UV/VIS Spectrometer, following the Di Stefano et al. methods (1989, 1997). The Folin-Ciocalteu index for total polyphenols was measured following the Method OIV-MA-AS2-10: R2009 (OIV, 2009). Colour intensity (CI) and tint (CT) were estimated by measuring absorbance at 420 , 520 and $620 \mathrm{~nm}$ (European Commission, 1990). The CIELAB parameters $\left(\mathrm{L}^{*}, \mathrm{a}^{*}, \mathrm{~b}^{*}, \mathrm{C}^{*}, \mathrm{H}^{*}\right)$ were determined following the recommendations of the Commission Internationale de L'Eclariage (CIE, 1986), and the CIE Yxy parameters were calculated with the Piracci 1994 software.

\section{Hydroxycinnamic acids, flavonols, organic acids and anthocyanins analysis}

An HPLC 1100 series Agilent technologies with binary pump and diode array detector (DAD) was used with a Thermo ODS RP-C18 Hypersil $200 \times 2.1(5 \mu \mathrm{m})$ column and a guard ODS Hypersil $20 \times 2.1 \mathrm{~mm}$ $(5 \mu \mathrm{m})$ for hydroxycinnamic acids and flavonols analysis according to Squadrito's et al. method (2007). For organic acids analysis a Phenomenex Synergi 4u Hydro-RP 80A $(250 \times 4.60 \mathrm{~mm}, 4 \mu \mathrm{m})$ with guard column was employed and the analysis was performed according to the method proposed by Cane (1990). The determination of anthocyanins (Hebrero et al., 1988) was performed on the same HPLC system with DAD detector set at $520 \mathrm{~nm}$, using a ODS Hypersil $(100 \times 2.1$, $5 \mu \mathrm{m})$ column with pre-column.

\section{Volatile compounds analysis}

Volatile compounds were detected and quantified using a C18 solid phase extraction/gas chromatography/mass spectrometry (SPE/GC/MS) technique described by Gianotti and Di Stefano (1991). GC-MS analysis was performed using a 6890 gas chromatograph interfaced with a 5973 mass selective detector (Agilent, Palo Alto, CA, USA). The column used was a HP-FFAP fused-silica open tubular column $(30 \mathrm{~m} \times 0.25 \mathrm{~mm} \times$ $0.25 \mu \mathrm{m}$ ) (Hewlett-Packard, Palo Alto, CA, USA) with a splitless system for $1 \mathrm{~min}$. Oven temperature was programmed at $50^{\circ} \mathrm{C}$ for $4 \mathrm{~min}$, to increase to $200^{\circ} \mathrm{C}$ at a rate of $3^{\circ} \mathrm{C} \mathrm{min}{ }^{-1}$, and then to hold $230^{\circ} \mathrm{C}$ for 10 min. The identification of compounds was performed using a NIST 75 library (using a percentage matching higher than $95 \%$ as the threshold 
value for acceptance) and comparing the linear retention index and the electron impact mass spectra with data from reference compounds.

\section{Sensory analysis}

Sensory analyses were conducted after 6 months of storage at the Agricultural Research Council, experimental winery of Barletta (Italy) performing a wine testing using a trained panel of tasters. The panellists were experts [members of wine organisations, such as the Italian National Organisation of Wine Tasters (ONAV)] qualified to make quality judgements. The wines of the experimental tests have been subjected to a descriptive analysis, for which a score sheet with a predetermined list of descriptors was used. The detectors were rated on an $80 \mathrm{~mm}$-unstructured line scale (Castino, 1983). The list of olfactory descriptors of Guinard and Noble (1986) was modified by adding the descriptors of colour and taste, as described in previous experimental works (Ubigli et al., 1991).

\section{Statistical analysis}

Multivariate statistical analysis was performed using $R$ Statistical Software [R Core Team (2013), R Foundation for Statistical Computing, Vienna, Austria]. The one way analysis of variance (ANOVA) and Tukey's multiple comparison test at a probability level of $\mathrm{P}<0.05$ were performed. Moreover, two principal component analyses (PCA) one on the volatile compounds, and another one on colour and phenolic components were carried out.

\section{Results}

\section{Chemical and physical characteristics of grapes and wines}

The grapes had the following chemical and physical characteristics: $3 \mathrm{~h}$ maceration: $22^{\circ}$ Brix, $\mathrm{pH} 3.52$ and total acidity $6.58 \mathrm{~g} \mathrm{~L}^{-1} ; 6 \mathrm{~h}$ maceration: $23^{\circ}$ Brix, $\mathrm{pH} 3.30$ and total acidity $6.73 \mathrm{~g} \mathrm{~L}^{-1} ; 8 \mathrm{~h}$ maceration: $22.8^{\circ}$ Brix, $\mathrm{pH} 3.32$ and total acidity $6.61 \mathrm{~g} \mathrm{~L}^{-1}$. The fundamental rosé wines components at racking are listed in Table 1 . The values of alcohol, dry extract as well as the profile of organic acids in wines do not deviate substantially, although $\mathrm{pH}$ and total acidity are inadequate in the $3 \mathrm{~h}$ maceration winemaking.

\section{Phenolic composition and anthocyanin profile}

Table 2 shows the polyphenolic composition of rosé wines at racking, after 6 and after 12 months. Comparing wines at racking, the differences are not significant for the total polyphenols while it is significantly different for total anthocyanins and proanthocyanidins. The amount of flavanols reacting with vanillin, which are low molecular weight tannins, the most bitter and astringent ones, is directly proportional to maceration time. The index of condensation $(\mathrm{V} / \mathrm{L})$, which is the ratio flavanols reacting with vanillin/proanthocyanidins, is generally low, but is higher in wines with $3 \mathrm{~h}$ of maceration compared to 6 and $8 \mathrm{~h}$ of maceration wines, resulting in a softer, more balanced and smoother structure of the latter. After six months and one year of stor-

Table 1. Chemical and physical composition of Bombino Nero rosé wines at racking.

\begin{tabular}{|c|c|c|c|}
\hline Parameters & $3 \mathrm{~h}$ & $\begin{array}{l}\text { Skin maceration time } \\
6 \mathrm{~h}\end{array}$ & $8 \mathrm{~h}$ \\
\hline Alcohol (\%) & $12.09 \pm 0.30^{\mathrm{a}}$ & $12.71 \pm 0.40^{\mathrm{ab}}$ & $12.67 \pm 0.40^{\mathrm{b}}$ \\
\hline Reducing sugars (g L $\mathrm{L}^{-1}$ ) & $2.4 \pm 0.6$ & $2.4 \pm 0.3$ & $2.4 \pm 0.7$ \\
\hline Reduced extract $\left(\mathrm{g} \mathrm{L}^{-1}\right)$ & $21.3 \pm 1.7$ & $20.8 \pm 1.5$ & $20.8 \pm 1.5$ \\
\hline $\mathrm{pH}$ & $3.60 \pm 0.10^{b}$ & $3.37 \pm 0.08^{\mathrm{a}}$ & $3.36 \pm 0.07^{\mathrm{a}}$ \\
\hline Total acidity $\left(\mathrm{g} \mathrm{L}^{-1}\right)$ & $4.51 \pm 0.27^{\mathrm{a}}$ & $5.20 \pm 0.30^{\mathrm{ab}}$ & $5.30 \pm 0.25^{b}$ \\
\hline Volatile acidity ( $\left.\mathrm{g} \mathrm{L}^{-1}\right)$ & $0.33 \pm 0.02^{b}$ & $0.24 \pm 0.02^{\mathrm{a}}$ & $0.33 \pm 0.02^{b}$ \\
\hline Total $\mathrm{SO}_{2}\left(\mathrm{mg} \mathrm{L}^{-1}\right)$ & $16.1 \pm 2.2 \mathrm{a}$ & $29.1 \pm 2.8 \mathrm{~b}$ & $38.2 \pm 3.1 \mathrm{c}$ \\
\hline Tartaric acid ( $\mathrm{g} \mathrm{L}^{-1}$ & $2.72 \pm 0.14^{\mathrm{a}}$ & $3.22 \pm 0.11^{\mathrm{ab}}$ & $3.31 \pm 0.12^{\mathrm{b}}$ \\
\hline Malic acid (g L $\left.\mathrm{L}^{-1}\right)$ & $1.32 \pm 0.09 c$ & $1.09 \pm 0.08^{b}$ & $0.80 \pm 0.05^{\mathrm{a}}$ \\
\hline Lactic acid $\left(\mathrm{g} \mathrm{L}^{-1}\right)$ & $0.45 \pm 0.02^{b}$ & $0.40 \pm 0.03^{\mathrm{ab}}$ & $0.38 \pm 0.02^{\mathrm{a}}$ \\
\hline
\end{tabular}

Values represent mean of three replicates \pm standard deviation. a,b,c Means not bearing a common letter differ significantly.

Table 2. Polyphenolic composition of Bombino Nero rosé wines $\left(\mathrm{mg} \mathrm{L}^{-1}\right)$.

\begin{tabular}{|c|c|c|c|c|c|c|c|c|c|}
\hline \multirow[t]{2}{*}{ Parameters } & \multicolumn{9}{|c|}{ Skin maceration time } \\
\hline & Racking & $\begin{array}{c}3 \mathrm{~h} \\
6 \text { months }\end{array}$ & 12 months & & $\begin{array}{c}6 \mathrm{~h} \\
6 \text { months }\end{array}$ & 12 months & Racking & $\begin{array}{c}8 \mathrm{~h} \\
6 \text { months }\end{array}$ & 12 months \\
\hline Total flavonoids* & $84.1 \pm 3.2^{\mathrm{aB}}$ & $63.4 \pm 2.4^{\mathrm{A}}$ & $61.4 \pm 2.8^{\mathrm{A}}$ & $167.6 \pm 7.1^{\mathrm{bB}}$ & $115.6 \pm 6.7^{\mathrm{A}}$ & $111.6 \pm 5.8^{\mathrm{A}}$ & $185.6 \pm 7.5 c^{B}$ & $122.5 \pm 6.3^{\mathrm{A}}$ & $120.1 \pm 5.9^{\mathrm{A}}$ \\
\hline Flavanols (Vanillin)* & $30.2 \pm 0.2^{\mathrm{aC}}$ & $20.2 \pm 0.2^{B}$ & $18.4 \pm 0.5^{\mathrm{A}}$ & $34.2 \pm 0.3 \mathrm{bC}$ & $28.6 \pm 0.3^{B}$ & $25.3 \pm 0.4^{\mathrm{A}}$ & $58.3 \pm 0.4^{\mathrm{cC}}$ & $37.2 \pm 0.4^{\mathrm{B}}$ & $33.1 \pm 0.3^{\mathrm{A}}$ \\
\hline Proanthocyanidins** & $90.2 \pm 3.4^{\mathrm{aC}}$ & $77.3 \pm 3.2^{\mathrm{B}}$ & $75.3 \pm 3.5^{\mathrm{A}}$ & $193.6 \pm 8.1^{\mathrm{bB}}$ & $155.4 \pm 7.4^{\mathrm{A}}$ & $144.4 \pm 6.5^{\mathrm{A}}$ & $224.5 \pm 8.8 c^{B}$ & $194.6 \pm 8.2^{\mathrm{A}}$ & $179.4 \pm 7.5^{\mathrm{A}}$ \\
\hline Total anthocyanins & $36.1 \pm 2.1^{\mathrm{aC}}$ & $23.3 \pm 1.2^{\mathrm{B}}$ & $17.2 \pm 1.1^{\mathrm{A}}$ & $45.4 \pm 1 . .^{\mathrm{bB}}$ & $44.3 \pm 1.8^{\mathrm{AB}}$ & $40.2 \pm 1.2^{\mathrm{A}}$ & $53.2 \pm 2.1^{\mathrm{c}}$ & $52.1 \pm 2.2$ & $50.0 \pm 2.0$ \\
\hline Monomeric anthocyans & $15.2 \pm 0.3^{\mathrm{aC}}$ & $9.1 \pm 0.2^{\mathrm{B}}$ & $10.2 \pm 0.2^{\mathrm{A}}$ & $23.3 \pm 0.4^{\mathrm{bC}}$ & $15.2 \pm 0.3^{B}$ & $14.3 \pm 0.3^{\mathrm{A}}$ & $25.2 \pm 0.4^{\mathrm{cC}}$ & $18.1 \pm 0.3^{\mathrm{B}}$ & $15.1 \pm 0.3^{\mathrm{A}}$ \\
\hline Index of condensation (V/L) & 0.33 & 0.26 & 0.26 & 0.17 & 0.18 & 0.19 & 0.26 & 0.19 & 0.18 \\
\hline
\end{tabular}

Values represent mean of three replicates \pm standard deviation. *Expressed as (+)-catechin; **expressed as cyanidin chloride. ${ }^{\mathrm{AB}, \mathrm{B}, \mathrm{C}}$ These were used in the comparison of wines at racking, 6 months and 12 months of storage. Means that do not bear a common letter differ significantly; a,b,cThese were used in the comparison of wines at the same sampling time (racking). The means that do not bear a common letter differ significantly. 
age, there is a reduction of polyphenolic compounds as previously reported in literature (Hernanz et al., 2009). The content of total anthocyanins shows an higher extent of reduction in $3 \mathrm{~h}$ of maceration wine compared to the 6 and $8 \mathrm{~h}$ of maceration ones, probably the presence of moderate amounts of tannins (proanthocyanidins and flavanols reacting with vanillin) is responsible of co-pigmentation reactions with anthocyanins, leading to an improvement of wine colour stabilisation by reducing anthocyanins losses, as previously reported in literature (Boulton, 2001). Table 3 shows that the anthocyanins in grape were mainly found as 3-monoglucosides (with malvidin-3G being the main one), followed by coumaroylated and acetylated anthocyanins. Also in the anthocyanins profile of Bombino Nero wines the malvidin-3monoglucoside was the main anthocyanin, followed by acetylated and coumaroylated anthocyanins. Anyway, the percentages found in the wines differ considerably from grape, as a result of both different solubility in water and different oxidability of the specific compound depending on its molecular structure, as found in previous works (Tamborra and Di Benedetto, 1991; Tamborra et al., 2003).

\section{Colour}

Figure 1 represents the visible absorbance spectra of rosé wines at racking and 12 months after racking. At $520 \mathrm{~nm}$ wavelength all the three winemaking processes showed an absorbance peak, due to absorption by anthocyanins, which was more pronounced at racking and reduced after one year of storage. Table 4 shows that at racking,

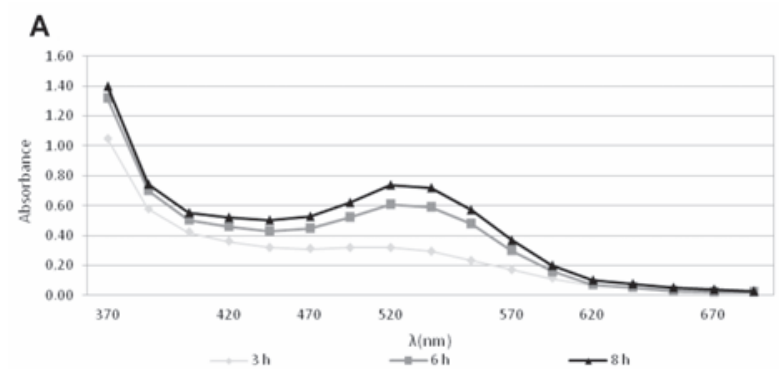

B

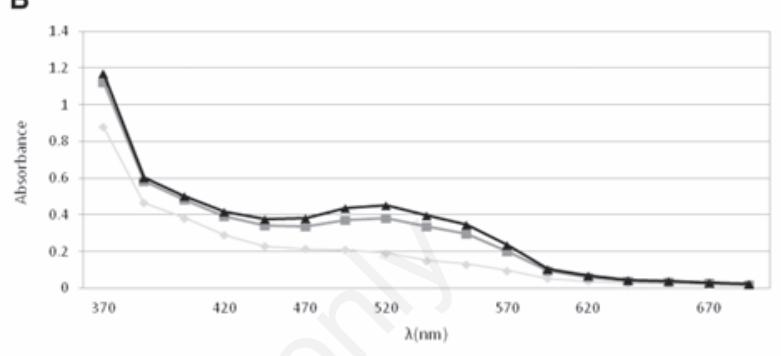

Figure 1. Absorbance spectra of Bombino Nero rosé wines at racking (A) and after 12 months $(B)$.

Table 3. The anthocyanins profile of Bombino Nero grape and rosé wines after 6 months of storage.

\begin{tabular}{lcccc} 
Parameters & Grape & 3 h & Skin maceration time \\
D h & 8 h & \\
Delphinidin-3G (\%) & 7.74 & 0.58 & 1.70 & 2.35 \\
Cyanidin-3G (\%) & 1.49 & 0.00 & 0.00 & 0.00 \\
\hline Petunidin-3G (\%) & 6.78 & 1.74 & 4.04 & 5.07 \\
Peonidin-3G (\%) & 5.21 & 2.47 & 3.40 & 3.72 \\
\hline Malvidin-3G (\%) & 42.02 & 79.59 & 69.97 & 67.72 \\
Total acetylated (\%) & 8.92 & 12.80 & 13.98 & 13.78 \\
\hline Total coumaroylated (\%) & 27.84 & 2.83 & 6.92 & 7.35 \\
\hline
\end{tabular}

Values represent mean of three (wine) or five (grape) replicates.

Table 4. Chromatic parameters of Bombino Nero rosé wines.

\begin{tabular}{|c|c|c|c|c|c|c|c|c|c|}
\hline \multirow[t]{2}{*}{ Parameters } & \multicolumn{9}{|c|}{ Skin maceration time } \\
\hline & Racking & $\begin{array}{c}3 \mathrm{~h} \\
6 \text { months }\end{array}$ & 12 months & Racking & 6 honths & 12 months & Racking & $\begin{array}{c}8 \mathrm{~h} \\
6 \text { months }\end{array}$ & 12 months \\
\hline Main wavelength & $583.8 \pm 4.2^{\mathrm{a}}$ & $578.8 \pm 4.6$ & $580.0 \pm 4.1$ & $620.5 \pm 5.3^{\mathrm{b}}$ & $590.5 \pm 4.8$ & $588.0 \pm 4.6$ & $633.2 \pm 6.2^{\mathrm{b}}$ & $593.5 \pm 4.9$ & $589.0 \pm 3.8$ \\
\hline Saturation S\% & $19.1 \pm 2.3^{\mathrm{AB}}$ & $16.9 \pm 2.9^{\mathrm{A}}$ & $24.7 \pm 2.6^{\mathrm{B}}$ & $20.2 \pm 3.1$ & $19.9 \pm 2.5$ & $20.5 \pm 3.2$ & $24.1 \pm 2.8$ & $21.7 \pm 3.3$ & $24.7 \pm 3.0$ \\
\hline $\mathrm{Y} \%$ & $64.1 \pm 3.4^{\mathrm{bA}}$ & $77.0 \pm 1.9^{\mathrm{B}}$ & $68.9 \pm 1.5^{\mathrm{A}}$ & $54.6 \pm 2.6^{\mathrm{aB}}$ & $61.0 \pm 2.4^{\mathrm{A}}$ & $62.3 \pm 2.8^{\mathrm{A}}$ & $50.1 \pm 2.1^{\mathrm{aA}}$ & $56.2 \pm 2.2^{\mathrm{A}}$ & $68.9 \pm 2.1^{\mathrm{B}}$ \\
\hline$L^{*}$ & $84.0 \pm 4.3$ & $90.3 \pm 3.9$ & $86.4 \pm 2.9$ & $74.5 \pm 5.1$ & $82.3 \pm 4.3$ & $83.1 \pm 3.5$ & $70.1 \pm 3.9$ & $79.7 \pm 5.3$ & $80.0 \pm 3.6$ \\
\hline$a^{*}$ & $6.31 \pm 1.7^{\mathrm{a}}$ & $5.08 \pm 1.9$ & $3.84 \pm 1.6$ & $8.25 \pm 2.8^{\mathrm{abA}}$ & $13.3 \pm 2.2^{\mathrm{AB}}$ & $14.6 \pm 2.1^{\mathrm{B}}$ & $13.8 \pm 2.1^{b}$ & $17.6 \pm 1.9$ & $17.3 \pm 1.9$ \\
\hline$b^{*}$ & $16.2 \pm 1.5$ & $16.3 \pm 1.4$ & $22.5 \pm 1.2$ & $13.5 \pm 1.9^{\mathrm{A}}$ & $15.5 \pm 1.3^{\mathrm{AB}}$ & $19.5 \pm 1.4^{\mathrm{B}}$ & $13.8 \pm 2.4$ & $15.9 \pm 2.6$ & $18.5 \pm 2.2$ \\
\hline $\mathrm{H}^{*}$ & $1.20 \pm 0.01^{\mathrm{bA}}$ & $1.50 \pm 0.01^{\mathrm{C}}$ & $1.40 \pm 0.03^{\mathrm{B}}$ & $0.45 \pm 0.01^{\mathrm{aA}}$ & $0.90 \pm 0.01^{\mathrm{B}}$ & $0.99 \pm 0.02^{\mathrm{C}}$ & $0.29 \pm 0.01^{\mathrm{aA}}$ & $0.73 \pm 0.01^{\mathrm{B}}$ & $1.40 \pm 0.02^{\mathrm{C}}$ \\
\hline $\mathrm{C}^{*}$ & $17.5 \pm 1.8^{\mathrm{aA}}$ & $16.3 \pm 1.6^{\mathrm{A}}$ & $22.8 \pm 1.9^{\mathrm{B}}$ & $28.9 \pm 2.3^{\mathrm{bB}}$ & $20.4 \pm 2.1^{\mathrm{A}}$ & $26.8 \pm 1.7^{\mathrm{B}}$ & $31.8 \pm 3.1^{\mathrm{bB}}$ & $23.7 \pm 2.8^{\mathrm{A}}$ & $22.8 \pm 1.7^{\mathrm{A}}$ \\
\hline $\mathrm{CI}$ & 0.76 & 0.53 & 0.59 & 1.14 & 0.83 & 0.82 & 1.35 & 0.94 & 0.93 \\
\hline CT & 1.20 & 1.52 & 1.45 & 0.76 & 1.02 & 1.20 & 0.70 & 0.92 & 1.02 \\
\hline
\end{tabular}

Values represent mean of three replicates \pm standard deviation. ${ }^{\mathrm{A}, \mathrm{B}, \mathrm{C}}$ These were used in the comparison of wines at racking, 6 months and 12 months of storage. Means that do not bear a common letter differ significantly; a,b,cThese were used in the comparison of wines at the same sampling time (racking). The means that do not bear a common letter differ significantly. 
with the increasing of residence time of the pomace with the must, both the maximum wavelength and the saturation (S\%) of colour significantly increase. The chromatic parameters for the $8 \mathrm{~h}$ maceration wine at racking indicate an intense red colour with violet hues, leading to a visual sensation of a brilliant red colour. The chroma value $\left(\mathrm{C}^{*}\right)$, increases with maceration time. In addition, the $\mathrm{CI}$ is higher in the $8 \mathrm{~h}$ maceration wine. In contrast, the lightness and the luminance ( $\mathrm{L}^{*}$ and $\mathrm{Y} \%$ ) are greater in wines with $3 \mathrm{~h}$ of maceration, therefore these wines show a higher transparency. The wine with $3 \mathrm{~h}$ of maceration had identical values of the chromatic parameters for hue both in CIELAB $\left(\mathrm{H}^{*}\right)$ and standard CT, signs of orange-red and yellow shades, due to a lower contribution of anthocyanins. The 6 and $8 \mathrm{~h}$ of maceration wines show moderate values for $\mathrm{H}^{*}$ and $\mathrm{CT}$, highlighting more red and lively shades. After 12 months of storage, the maximum wavelength value decreased to a greater extent for wines with $8 \mathrm{~h}$ of maceration, while the value for the saturation ( $\mathrm{S} \%$ ) increased only for wine with $3 \mathrm{~h}$ of maceration. The luminance $(\mathrm{Y} \%)$ increased in all wines.

\section{Hydroxycinnamic acids and flavonols}

Among hydroxycinnamic acids esterified with tartaric acid, the trans-caffeoyl tartaric acid (i.e. trans-caftaric acid), which is the prevalent one, was significantly lower in the winemaking with $3 \mathrm{~h}$ of maceration (Table 5) instead the other winemaking processes were richer in this compound. The $3 \mathrm{~h}$ maceration wine had an higher concentration of caffeic and trans-fertaric acids. After 12 months from racking, there is an increase of acids in the free state, likely due to the hydrolysis of the corresponding esters (Cheynier et al., 1990). The highest caffeic acid content, even after 12 months, is found in the winemaking with 3 $\mathrm{h}$ of maceration. The investigated flavonols (i.e. glycosilated forms of myricetin, quercetin and kaempferol) were found in rather small quantities. Regarding these compounds, the soaking time did not produced noticeable differences between wines.

\section{Volatile compounds}

Table 6 shows the contents of these volatile compounds, expressed as $\mu \mathrm{g} \mathrm{L}^{-1}$ of 1-heptanol. To determine the influence of the compounds detected by GC onto the perception of aroma it was calculated the odour activity value $(\mathrm{OAV})$, which is defined as the concentration of a single compound divided by the odour threshold (i.e. the lowest concentration that can be detected by human nose). The results show how the $6 \mathrm{~h}$ maceration wine is the richest in isoamyl acetate, responsible for scents of melon and banana, and hexyl acetate (fruity scent). Isoamyl acetate was higher than its perception threshold (Gòmez-Mìguez et al., 2007) and OAV >1. The hexyl acetate with a perception threshold (Pino and Quijano, 2012) had OAV >1. The ethyl esters of fatty acids, able to confer olfactory notes related to fruits, ethyl n-butanoate, hexanoate and octanoate had an $0 \mathrm{AV}>1$ in all the three wines but were higher in the $6 \mathrm{~h}$ maceration wine in which almost doubled the other two wines. The 2-phenyl ethyl acetate (scent of roses), is higher in the $6 \mathrm{~h}$ maceration wine, closer to its detection threshold (Gòmez-Mìguez et al., 2007), anyway it does not show concentrations higher than its detection threshold in any wine. The content of ethyl decanoate is lower in the $6 \mathrm{~h}$ maceration wine, which represents a positive feature since this compound, gives soapy notes, lending a wine a less fine aroma. Ethyl decanoate with a perception threshold (Gòmez-Mìguez et al., 2007) had $0 \mathrm{AV}>1$. The hexanol with a detection threshold (Gòmez-Mìguez et al., 2007) showed an $0 A V>1$ for the 6 and $8 \mathrm{~h}$ wines. In all wines it was found a limited content (lower than the detection threshold) of vinyl phenols, which are able to confer an unpleasant medicinal odour in higher amounts (McMurrough et al., 1996).

\section{Sensory profile}

Figure 2 shows that the wine with $3 \mathrm{~h}$ of maceration had lower colour intensity, showing an onion skin colour, with less pronounced violet hues. The wines with 6 and 8 h of maceration had a similar colour, more like a light cherry pink colour, that was slightly more pronounced in the wine with $8 \mathrm{~h}$ of maceration. Olfactory notes of cherries, exotic fruits and berries were mainly observed in the $6 \mathrm{~h}$ of maceration wine, therefore this wine was evaluate as more fragrant and delicate. The wine with the $3 \mathrm{~h}$ of maceration had a less acidic taste, was velvety and poorly structured. The same features have been also observed in the other two wines, even if were most intense in $6 \mathrm{~h}$ maceration wine then in the $8 \mathrm{~h}$ maceration wine.

\section{Principal component analysis}

A first PCA was carried out on the three winemaking using the volatile compounds as variables. The main variables which participated in the construction of the PC1 (Figure 3) were 1-hexanol, (E)-3-hexen1-ol, (Z)-3-hexen-1-ol, ethyl lactate, 2-and 3-methyl-1-butanol, all with positive correlation coefficients and 4-vinyl phenol with a negative correlation coefficient. Instead, in the construction of PC2, the main participants were ethyl butanoate, isoamyl acetate, ethyl hexanoate, hexyl acetate, ethyl octanoate, diethyl succinate, 2-phenylethyl ester of acetic acid, all with negative correlation coefficients. Considering the odour

Table 5. Flavonols and hydroxycinnamic acids in Bombino Nero rosé wines $\left(\mathrm{mg} \mathrm{L}^{-1}\right)$.

\begin{tabular}{|c|c|c|c|c|c|c|c|c|c|}
\hline \multirow[t]{2}{*}{ Parameters } & \multicolumn{9}{|c|}{ Skin maceration time } \\
\hline & Racking & $\begin{array}{c}3 \mathrm{~h} \\
6 \text { months }\end{array}$ & 12 months & Racking & $\begin{array}{c}6 \mathrm{~h} \\
6 \text { months }\end{array}$ & 12 months & Racking & $\begin{array}{c}8 \mathrm{~h} \\
6 \text { months }\end{array}$ & 12 months \\
\hline t-caffeoyl tartaric acid & $20.2 \pm 0.8^{\mathrm{aC}}$ & $18.6 \pm 0.5^{\mathrm{B}}$ & $16.7 \pm 0.2^{\mathrm{A}}$ & $52.9 \pm 3.8^{b}$ & $50.4 \pm 3.5$ & $49.2 \pm 3.4$ & $66.8 \pm 5.4^{c}$ & $65.2 \pm 4.6$ & $60.2 \pm 3.9$ \\
\hline t-p-coumaroyl tartaric acid & $3.0 \pm 0.3^{\mathrm{c}}$ & $3.1 \pm 0.2$ & $2.7 \pm 0.2$ & $2.3 \pm 0.3^{b}$ & $2.2 \pm 0.2$ & $2.2 \pm 0.2$ & $1.5 \pm 0.2^{\mathrm{a}}$ & $1.4 \pm 0.1$ & $1.5 \pm 0.1$ \\
\hline t-fertaric acid & $10.3 \pm 0.6^{b}$ & $10.0 \pm 0.7$ & $9.3 \pm 0.6$ & $4.2 \pm 0.9^{\mathrm{a}}$ & $3.2 \pm 0.5$ & $4.5 \pm 0.6$ & $3.5 \pm 0.3^{\mathrm{a}}$ & $3.8 \pm 0.2$ & $4.2 \pm 0.5$ \\
\hline caffeic acid & $17.0 \pm 1.1^{\mathrm{b}}$ & $19.6 \pm 1.2$ & $19.8 \pm 1.5$ & $7.2 \pm 1.3^{\mathrm{a}}$ & $7.8 \pm 0.9$ & $8.5 \pm 0.8$ & $6.8 \pm 0.6^{\mathrm{a}}$ & $8.1 \pm 0.8$ & $8.4 \pm 0.7$ \\
\hline p-coumaric acid & $3.6 \pm 0.3^{\mathrm{bA}}$ & $4.1 \pm 0.4^{\mathrm{A}}$ & $7.9 \pm 0.5^{\mathrm{B}}$ & $2.9 \pm 0.6 \mathrm{abA}$ & $3.2 \pm 0.4^{\mathrm{A}}$ & $6.0 \pm 0.6^{\mathrm{B}}$ & $2.2 \pm 0.4^{\mathrm{aA}}$ & $2.7 \pm 0.3^{\mathrm{A}}$ & $5.9 \pm 0.4^{\mathrm{B}}$ \\
\hline ferulic acid & $2.1 \pm 0.2^{\mathrm{aB}}$ & $1.8 \pm 0.2^{\mathrm{B}}$ & $0.4 \pm 0.1^{\mathrm{A}}$ & $2.9 \pm 0.4^{\mathrm{abA}}$ & $3.9 \pm 0.4^{\mathrm{B}}$ & $2.8 \pm 0.3^{\mathrm{A}}$ & $2.8 \pm 0.3^{b}$ & $3.1 \pm 0.2$ & $2.7 \pm 0.3$ \\
\hline Myricetin* & $0.20 \pm 0.10$ & $0.10 \pm 0.10$ & $0.10 \pm 0.00$ & $0.18 \pm 0.15$ & $0.15 \pm 0.10$ & $0.12 \pm 0.10$ & $0.20 \pm 0.10$ & $0.15 \pm 0.10$ & $0.15 \pm 0.10$ \\
\hline Quercetin* & $0.22 \pm 0.10^{\mathrm{a}}$ & $0.12 \pm 0.10$ & $0.11 \pm 0.10$ & $2.78 \pm 0.10^{\mathrm{bB}}$ & $1.50 \pm 0.10^{\mathrm{A}}$ & $1.30 \pm 0.10^{\mathrm{A}}$ & $3.60 \pm 0.10^{c c}$ & $2.10 \pm 0.1^{0 \mathrm{~B}}$ & $1.10 \pm 0.10^{\mathrm{A}}$ \\
\hline Kaempferol* & $0.42 \pm 0.10^{a}$ & $0.40 \pm 0.10$ & $0.40 \pm 0.10$ & $1.85 \pm 0.10^{\mathrm{bB}}$ & $0.67 \pm 0.10^{\mathrm{A}}$ & $0.74 \pm 0.10^{\mathrm{A}}$ & $1.20 \pm 0.10^{\mathrm{cB}}$ & $0.80 \pm 0.10^{\mathrm{A}}$ & $0.70 \pm 0.10^{\mathrm{A}}$ \\
\hline
\end{tabular}

*Sum of two glycosides: glucuronide and glucoside. Values represent mean of three replicates \pm standard deviation. $\mathrm{A}, \mathrm{B}, \mathrm{C}$ These were used in the comparison of wines at racking, 6 months and 12 months of storage.

Means that do not bear a common letter differ significantly; a,b,cThese were used in the comparison of wines at the same sampling time (racking). The means that do not bear a common letter differ significantly. 
characteristics of the compounds contributing to the PCs, the PCl could account for freshly cut grass, buttery, with hints of fruit aromas. Instead the PC2 could be considered the axis of all the esters with fruity odour. Another PCA was also performed using colour parameters and the phenolic components of wines at racking (Figure 4). Among the main variables, which participate in the construction of the PC1, with positive correlation coefficients, are almost all the phenolic compounds, with the total anthocyanins showing the highest value. Also the colour indices hue and luminosity show correlation coefficients which are higher for PC1 but with a negative sign. The main contributors to PC2 are total polyphenols, flavonols reacting with vanillin (the most bitter ones) and colour saturation.

\section{Discussion and conclusions}

The aim of this work was to investigated how different time of contact with skin during pre-fermentative maceration performed in an actual winery at a fixed temperature for 3,6 and $8 \mathrm{~h}$ can affect rosé wine characteristics such as colour and the phenolic and volatile composition, both at racking and over time. It was chosen to employ an already appreciated grape, the Bombino Nero, which recently produced a wine that was awarded with silver medal at Mondial du rosé 2013. Concerning the phenolic composition, since the extraction of polyphenolic compounds is a function of the maceration time, increasing the residence time of the pomace with the must, also increases the concentration of the various phenolic constituents in wine. Anyway, the amount of change depends on the specific class of polyphenolic substances. Three hour-maceration wine had a total polyphenolic content comparable to the other two wines but a lower content of flavanols and total anthocyanins since the minimal amount of time for the maceration did not favoured the extraction of these antioxidant compounds which have many alleged health benefits (López-Vélez et al., 2003). Concerning the anthocyanins profile of Bombino Nero wines, it must be underlined that there is a difference between grape and wines profile since anthocyanins are implicated in chemical reactions (oxidation or covalent linking with other compounds) and form intermolecular bonds (hydrogen bonds and hydrophobic interactions) resulting in copigmentation complexes. The relationship between the red colour of wine and anthocyanins content is related to the co-pigmentation compounds resulting from interactions between anthocyanins and other colourless molecules, which determinates in the wines with an higher content anthocyanins, i.e. 6 and $8 \mathrm{~h}$ of maceration ones, a much higher intensity than would be expected from the concentration of the single anthocyanins. The Bombino Nero rosé wine with $3 \mathrm{~h}$ of maceration already at racking showed a yellow hue that dominated the red colour. Moreover, it was provided of less phenolic substances with antioxidant action that are not only able to preserve colour over time, but also lead to a lower susceptibility to oxidation, therefore it was more exposed to browning and colour change. Concerning the colour stability both 6 and $8 \mathrm{~h}$ of maceration wines, thus richer of those antioxidant compounds that are able to preserve colour, are indeed less likely to lose their colour over time. Bombino Nero is a neutral grape variety poor of aromatic varietal compounds such as terpenes and norisoprenoids (Tamborra and Pigella, 1999). However, appropriate winemaking techniques, may facilitate the formation of fermentation volatile compounds (secondary aromas), which are responsible for the fruity aromas of young wines (Losada et al., 2012). The GC analysis showed that the $6 \mathrm{~h}$ maceration wine was rich in various pleasant fruity and flowery scents, which in some cases almost doubled the amounts present in the other wines. A further advantage of the $6 \mathrm{~h}$ maceration compared to the $8 \mathrm{~h}$ one, is the production of a wine with a significantly lower content of hexanol, responsible for herbaceous notes. Accordingly with GC analysis, the sensory analysis performed after 6 months of storage showed a preference of testers for the $6 \mathrm{~h}$ of maceration wine.

Table 6. Volatile compounds of rosé wines from Bombino Nero after 6 months of storage $\left(\mu \mathrm{g} \mathrm{L}^{-1}\right)$.

\begin{tabular}{|c|c|c|c|}
\hline \multirow[t]{2}{*}{ Compound } & \multicolumn{3}{|c|}{ Skin maceration time } \\
\hline & $3 \mathrm{~h}$ & $6 \mathrm{~h}$ & $8 \mathrm{~h}$ \\
\hline ethyl butanoate & $161 \pm 17^{\mathrm{a}}$ & $290 \pm 22^{b}$ & $113 \pm 7^{c}$ \\
\hline isoamyl acetate & $478 \pm 56^{\mathrm{a}}$ & $6247 \pm 472^{b}$ & $2605 \pm 75^{c}$ \\
\hline ethyl hexanoate & $371 \pm 17^{a}$ & $784 \pm 33^{b}$ & $416 \pm 40^{\mathrm{a}}$ \\
\hline hexyl acetate & $14 \pm 3^{\mathrm{a}}$ & $247 \pm 20^{\mathrm{b}}$ & $177 \pm 22^{c}$ \\
\hline ethyl lactate & $19 \pm 3^{\mathrm{a}}$ & $22 \pm 5^{\mathrm{ab}}$ & $29 \pm 4^{b}$ \\
\hline ethyl octanoate & $499 \pm 65^{\mathrm{a}}$ & $861 \pm 61^{b}$ & $340 \pm 27^{c}$ \\
\hline 3-hydroxy butanoic acid ethyl ester & $8 \pm 2^{\mathrm{a}}$ & $18 \pm 6^{b}$ & $21 \pm 2^{b}$ \\
\hline ethyl decanoate & $621 \pm 68^{\mathrm{ab}}$ & $541 \pm 41^{\mathrm{a}}$ & $702 \pm 45^{b}$ \\
\hline diethyl succinate & $73 \pm 7^{\mathrm{a}}$ & $107 \pm 15^{b}$ & $79 \pm 7^{\mathrm{a}}$ \\
\hline 2-phenylethyl acetate & $18 \pm 3^{\mathrm{a}}$ & $211 \pm 23^{b}$ & $99 \pm 9 c$ \\
\hline diethyl malate & $85 \pm 8^{a}$ & $152 \pm 17^{b}$ & $140 \pm 23^{b}$ \\
\hline 2 and 3-methyl-1-butanol & $9138 \pm 768^{a}$ & $9968 \pm 835^{\mathrm{a}}$ & $11,941 \pm 894^{\mathrm{b}}$ \\
\hline 1-hexanol & $314 \pm 34^{\mathrm{a}}$ & $622 \pm 40^{\mathrm{b}}$ & $915 \pm 46^{c}$ \\
\hline (E)-3-hexen-1-ol & $13 \pm 2^{\mathrm{a}}$ & $15 \pm 2^{\mathrm{ab}}$ & $20 \pm 2^{b}$ \\
\hline (Z)-3-hexen-1-ol & $20 \pm 2^{\mathrm{a}}$ & $22 \pm 1^{a b}$ & $28 \pm 3^{b}$ \\
\hline benzyl alcohol & $19 \pm 2$ & $18 \pm 1$ & $18 \pm 3$ \\
\hline phenyl ethyl alcohol & $12,458 \pm 993^{\mathrm{a}}$ & $11,057 \pm 315^{\mathrm{a}}$ & $14,880 \pm 1272^{b}$ \\
\hline 4-vinyl guaiacol & $26 \pm 7$ & $24 \pm 7$ & $29 \pm 7$ \\
\hline 4-vinyl phenol & $33 \pm 8$ & $32 \pm 5$ & $31 \pm 2$ \\
\hline
\end{tabular}


Nevertheless also the winemaking with $8 \mathrm{~h}$ of maceration was recognised to possess a sensory profile of considerable prestige. In the PCA carried out using the volatile compounds as variables, the different wines are spread in the plot, which confirms the differences among the wines. The $3 \mathrm{~h}$ maceration wine has less intense aromas, the $6 \mathrm{~h}$ maceration wine is characterised by the most intense fruit aroma of the three winemaking and has almost no hints of fresh cut grass, and the $8 \mathrm{~h}$ maceration wine has a more fresh grass aroma with just hints of fruit. These results confirm the differences among the wines already found by the sensory analysis. The second PCA shows that the wine obtained with $3 \mathrm{~h}$ of maceration time has a poor content of coloured compounds, a feature that is reflected in colour indices such as hue and colour intensity. The 6 and $8 \mathrm{~h}$ of maceration wines are both rich of flavonoids (anthocyanins, proanthocyanidins, flavonols) and hydroxycinnamoyl tartaric acids, but the $8 \mathrm{~h}$ of maceration wine is characterised by more flavan-3-ols, the most bitter and astringent ones and higher colour saturation, compared to the 6 h maceration wine. The statistical analyses performed showed a correspondence between features described by the panel of testers and the actual composition of wines in terms of volatile compounds and, moreover, a relationship between colour indices and phenolic components of wines. The analyses have also been performed after 12 months of wine aging, a period embracing their commercial life. As expected, it was found a general decrease of volatile compounds and a worsening of colour parameters for each wine, especially for the $3 \mathrm{~h}$ of maceration one. It was chosen to perform the experimental winemaking in a winery instead of a laboratory small-scale fermentation study that needs further evaluation in a real winery context. This preliminary study helped to evaluate feasibility and to identify possible issues in the proposed rosé wine winemaking processes. The main advantage was to obtain results easy to translate into practical winemaking management suggestions thus directly usable for winemakers.

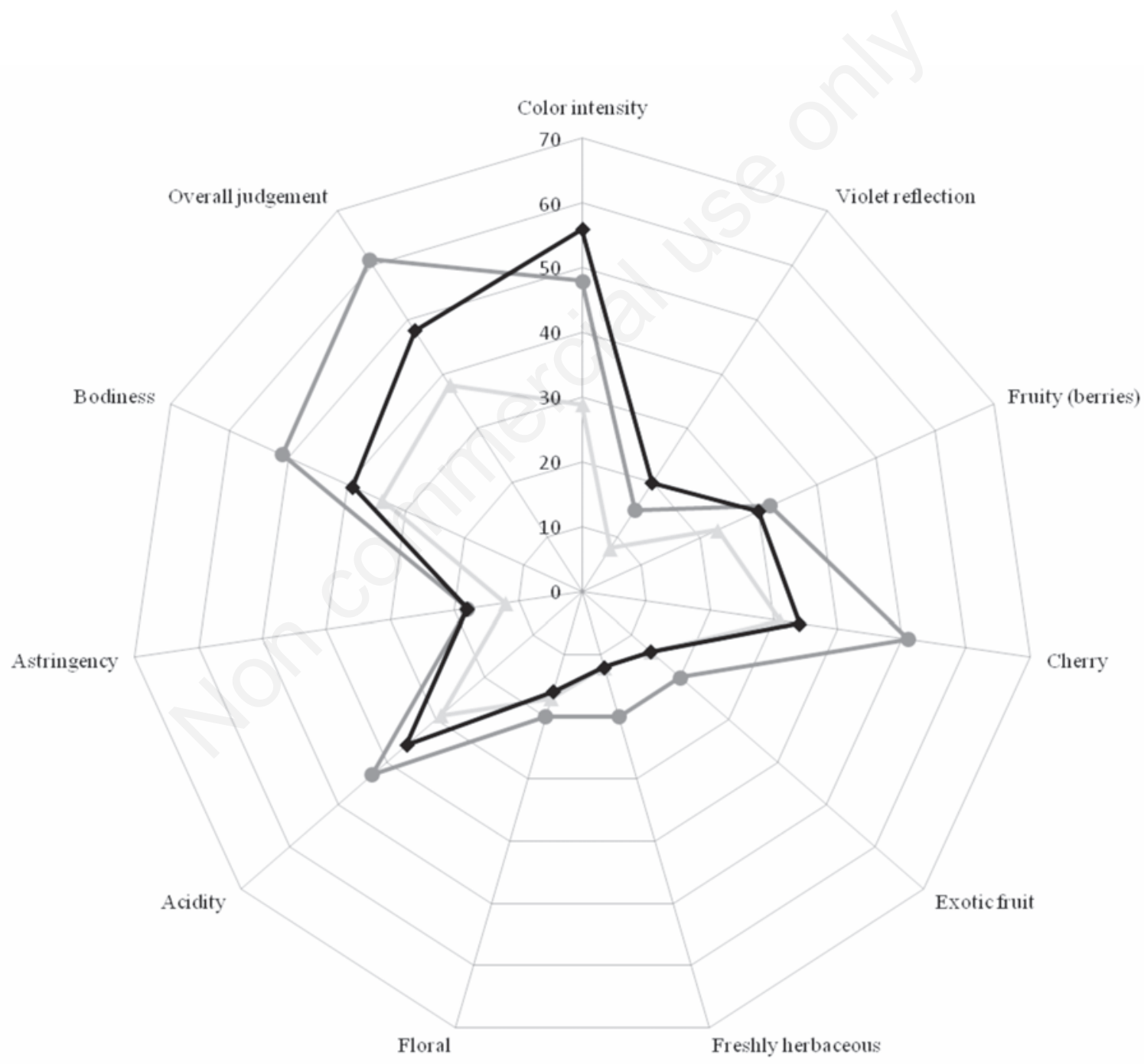




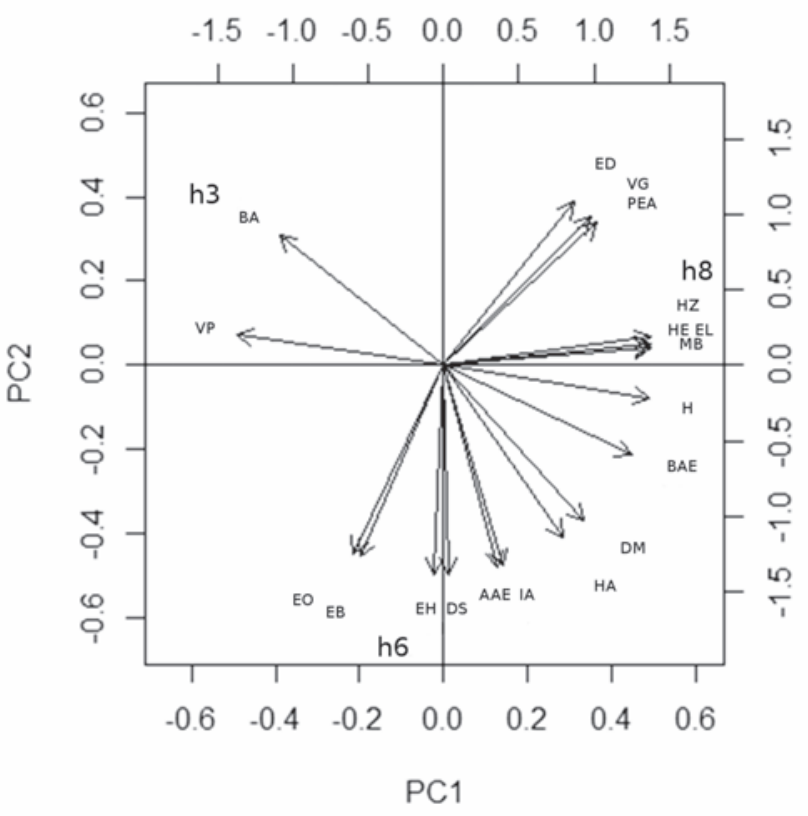

Figure 3. Principal components analysis (PCA) of volatile compounds. EB, ethyl butanoate; IA, isoamyl acetate; $E H$, ethyl hexanoate; HA, hexyl acetate; EL, ethyl lactate; EO, ethyl octanoate; BAE, butanoic acid 3-hydroxy ethyl ester; ED, ethyl decanoate; DS, diethyl succinate; AAE, acetic acid-2-phenylethyl ester; DM, diethyl malate; MB, 2,3-methyl-1-butanol; $H, 1$ hexanol; HE, (E)-3-hexen-1-ol; HZ, (Z)-3-hexen-1-ol; BA, benzyl alcohol; PEA, phenyl ethyl alcohol; VG, 4-vinyl guaiacol; VP, 4-vinyl phenol.

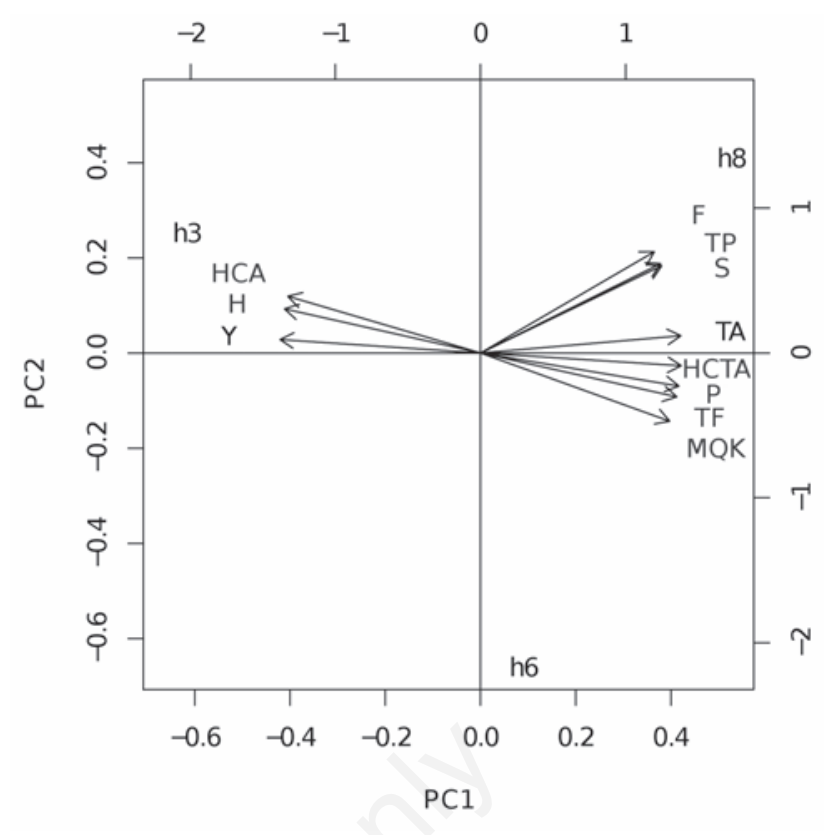

Figure 4 Principal components analysis (PCA) of colour and phenolic components. TP, total polyphenols; TF, total flavonoids; F, flavan-3-ols; P, proanthocyanidins; TA, total anthocyanidins; MQK, sum of main flavonols; HCTA, sum of hydroxycinnamoyl tartaric acids; HCA, sum of hydroxycinnamic acids; $S$, saturation; $H$, hue; $Y$, luminosity

Phytochem. 29:1751-3.

CIE (Commission Internationale de l'Éclairage), 1986. Colourimetry, 2nd ed. Publication No. CIE 15.2. Central Bureau of the CIE, Vienna, Austria.

Di Stefano R, 2010. La vinificazione dei rosati in Italia. Atti Accademia Italiana della Vite e del Vino 29. No. 87. Available from: http://www.aivv.it/index.php/2011-10-11-21-44-22.html?chronoform $=$ frm_Relazioni\&order $=I D \_A r g \& d i r e c t i o n=a s c \& s t a r t=60$

Di Stefano R, Cravero MC, Gentilini N, 1989. Metodi per lo studio dei polifenoli dei vini. L'Enotecnico. 25:83-9.

Di Stefano R, Ummarino I, Gentilini N, 1997. Alcuni aspetti del controllo di qualità nel campo enologico. Lo stato di combinazione degli antociani. Asti Ann. Ist. Sper. Enol. 27:105-21.

European Commission, 1990. Commission Regulation (EEC) No 2676/90 of 17 September 1990 determining Community methods for the analysis of wines. In: Official Journal, L272, 3/10/1990, available from: http://eur-lex.europa.eu/legal-content/EN/ALL/?uri= CELEX:31990R2676

Fuhrman B, Volkova N, Suraki A, Aviram M, 2001. White wine with red wine-like properties: increased extraction of grape skin polyphenols improves the antioxidant capacity of the derived white wine. J. Agric. Food Chem. 49: 3164-8.

Gianotti S, Di Stefano R, 1991. Metodo per la determinazione dei composti volatili di fermentazione. L'Enotecnico. 10:61-4.

Gòmez-Mìguez MJ, Cacho JF, Ferreira V, Vicario IM, Heredia FJ, 2007. Volatile components of Zalema white wines. Food Chem. 100:1464-73.

Guinard JX, Noble AC, 1986. Proposition of a terminology for the analytical description of the aroma wines. Sci. Aliment. 6:657-62. 
Hebrero E, Santos-Buelga C, Rivas-Gonzalo JC, 1988. High performance liquid chromatography-diode array spectroscopy identification of anthocyanins of vitis vinifera variety Tempranillo. Am. J. Enol. Viticult. 39:227-33.

Hernanz D, Gallo V, Recamales ÁF, Meléndez-Martínez AJ, GonzálezMiret ML, Heredia FJ, 2009. Effect of storage on the phenolic content, volatile composition and colour of white wines from the varieties Zalema and Colombard. Food Chem. 113:530-7.

López-Vélez M, Martínez-Martínez F, Del Valle-Ribes C, 2003. The study of phenolic compounds as natural antioxidants in wine. Crit. Rev. Food Sci. Nutr. 43:233-44.

Losada MM, López JF, Añón A, Andrés J, Revilla E, 2012. Influence of some oenological practices on the aromatic and sensorial characteristics of white Verdejo wines. Int. J. Food Sci. Tech. 47:1826-34.

Marais J, 1983. Terpenes in the aroma of grapes and wines: a review. S. Afr. J. Enol. Vitic. 4:49-58.

Marais J, Rapp A, 1988. Effect of skin contact time and temperature on juice and wine composition and wine quality. S. Afr. J. Enol. Vitic. 9:22-30.

McMurrough I, Madigan D, Donnelly D, Hurley J, Doyle AM, HenniganG, McNulty N, Smyth MR, 1996. Control of ferulic acid and 4-vinyl guaiacol in brewing. J. Inst. Brew. 102:327-32.

OIV (Organisation Internationale de la Vigne et du Vin), 2009. Compendium of international methods of analysis - OIV, FolinCiocalteu Index, Method OIV-MA-AS2-10: R2009, 1. Available from: http://www.oiv.int/oiv/files/6\%2520-\%2520Domaines\%2520scientifiques/6\%2520-\%25204\%2520Methodes\%2520d\%2520analyses/64-1/EN/OIV-MA-AS2-10.pdf

Pino JA, Quijano CE, 2012. Study of the volatile compounds from plum (Prunus domestica L. cv. Horvin) and estimation of their contribution to the fruit aroma. Ciên. Tec. Aliment. 32:76-83.
Piracci A, 1994. Évaluation instrumentale de la couleur. J. Int. Sci. Vigne Vin. 28:247-51.

Ramey D, Bertrnad A, Ough CS, Singleton VL, Sanders E, 1986. Effects of skin contact temperature on Chardonnay must and wine composition. Am. J. Enol. Viticult. 37:99-106.

Ramey D, Ough CS, 1980. Volatile ester hydrolysis or formation during storage of model solution and wines. J. Agric. Food Chem. 28:928-34.

Salinas MR, Garijo J, Pardo F, Zalacain A, Alonso GL, 2003. Colour, polyphenol, and aroma compounds in rosé wines after prefermentativa maceration and enzymatic treatments. Am. J. Enol. Viticult. 54:195-202.

Salinas MR, Garijo J, Pardo F, Zalacain A, Alonso GL, 2005. Influence of prefermentative maceration temperature on the colour and the phenolic and volatile composition of rosé wines. J. Sci. Food Agric. 85:1527-36.

Şener H, Yildirim HK, 2013. Influence of different maceration time and temperatures on total phenols, colour and sensory properties of Cabernet Sauvignon wines. Food Sci. Tech. Int. 19:523-33.

Squadrito M, Corona 0, Ansaldi G, Di Stefano R, 2007. Relazione fra i percorsi biosintetici degli HCTA, dei flavonoli e degli antociani nella buccia dell'uva. Riv. Vitic. Enol. 3:59-70.

Tamborra P, Di Benedetto G, 1991. Il profilo fenolico di alcune varietà di uve a bacca nera coltivate in Puglia. L'Enotecnico. 27:89-96.

Tamborra P, Esti M, Minafra M, Sinesio F, 2003. Phenolic compounds in red-berry skins of Uva di Troia and Bombino Nero grapes (Vitis vinifera L.). It. J. Food Sci. 15:347-57.

Tamborra P, Pigella R, 1999. Precursori d'aroma presenti nelle uve a sapore neutro Bombino n. ed Uva di Troia. Riv. Vitic. Enol. 52:15-22.

Ubigli M, Rissone M, Gerbi V, Anfosso P, 1991. Analisi strumentali e sensoriali del Barbaresco D.0.C.G. Riv. Vitic. Enol. 44:47-65. 